\title{
Produtividade de Pinus caribaea VAR. hondurensis e suas relações com atributos químicos dos solos em região de Cerrado brasileiro
}

\author{
Productivity of Pinus caribaea VAR. hondurensis and its relations with chemical attributes of \\ soils in the brazilian Cerrado region
}

\author{
Vinicius Evangelista Silva ${ }^{\mathrm{I}}$, Paulo Ricardo Teodoro da Silva" ${ }^{\mathrm{II}}$, Rafael Montanari"II, \\ Sara Dias da Silva Lisboa ${ }^{\text {II }}$ Edmar Roberto Bellati Batello ${ }^{\mathrm{II}}$, Jailson Vieira Aguilar", \\ Lucas Aparecido Manzani Lisboa ${ }^{\mathrm{II}}$, Marlon Marino Albertini ${ }^{\mathrm{II}}$
}

\begin{abstract}
Resumo
A silvicultura com espécies exóticas desempenha importante papel socioeconômico no Brasil, fornecendo matéria-prima para a produção de madeira, lenha, carvão vegetal, celulose, dentre outros. Nesse sentido, torna-se necessário o aprofundamento do conhecimento sobre as variáveis ambientais que controlam a produtividade do Pinus; em especial, as edáficas. O objetivo do presente trabalho foi avaliar a variabilidade espacial dos atributos químicos de solo e planta em um plantio comercial de Pinus caribaea var. hondurensis. O experimento foi instalado no campus da Faculdade de Engenharia de Ilha Solteira (Unesp), localizado em Selvíria, Estado de Mato Grosso do Sul, Brasil, em um Latossolo Vermelho Distroférrico, textura muito argilosa. Foram analisados os seguintes atributos químicos do solo: fósforo $(\mathrm{P})$, matéria orgânica $(\mathrm{MO})$, potencial hidrogeniônico $(\mathrm{pH})$, potássio $(\mathrm{K})$, cálcio $(\mathrm{Ca})$, magnésio $(\mathrm{Mg})$, acidez potencial $(\mathrm{H}+\mathrm{Al})$, alumínio $(\mathrm{Al})$, soma de bases $(\mathrm{SB})$, capacidade de troca catiônica (CTC), saturação por bases (V\%), cálcio (CaT), magnésio (MgT) e alumínio (m) na CTC (Capacidade de Troca Catiônica). Todos os atributos de solo e planta apresentaram dependência espacial simples na área do estudo, exceto Altura, Diâmetro a Altura do Peito e acidez potencial na camada de 0,10-0,20 m, evidenciando que o manejo de Pinus pode ser realizado de acordo com site específico nas condições do estudo. O potássio foi o atributo de solo que melhor se correlacionou com a produtividade de Pinus em volume, bem como os melhores indicadores para a estimativa da produtividade.
\end{abstract}

Palavras-chave: Química do solo; Krigagem; Silvicultura; Variabilidade

\begin{abstract}
Forestry with exotic species plays an important socioeconomic role in Brazil, providing raw material for the production of wood, firewood, charcoal, cellulose, among others. In this sense, it becomes necessary to deepen the knowledge about the environmental variables that control the productivity of Pinus, especially the edaphic ones. The objective of the present work was to evaluate the spatial variability of soil and plant chemical attributes in a commercial plantation of Pinus caribaea var. Hondurensis. The experiment was installed on the campus of the Faculty of Engineering of Ilha Solteira (Unesp), located in Selvíria, state of Mato Grosso do Sul, Brazil, in a RED OXYSOL Dystroferric, very clayey texture. The following soil chemical attributes were analyzed: phosphorus $(\mathrm{P})$, organic matter $(\mathrm{OM})$, hydrogen ionic potential $(\mathrm{pH})$, potassium $(\mathrm{K})$, calcium $(\mathrm{Ca})$, magnesium $(\mathrm{Mg})$, potential acidity $(\mathrm{C})$, base saturation $(\mathrm{V} \%)$, calcium $(\mathrm{CaT})$, magnesium $(\mathrm{MgT})$ and aluminum $(\mathrm{m})$ in $\mathrm{CEC}$ (Cationic Exchange Capacity). All soil and plant attributes presented simple spatial dependence in the studied area, except for height, diameter at breast height and potential acidity in the 0.10-0.20 m layer, evidencing that Pinus management can be performed according to the specific site in the conditions of the study. Potassium was the soil attribute that best correlated with the productivity of Pinus in volume, as well as the best indicators for the estimation of productivity.
\end{abstract}

Keywords: Soil chemistry; Kriging; Forestry; Variability

\footnotetext{
I Engenheiro Florestal, MSc., Especialista em Nutrição e Manejo Florestal, Eldorado Brasil Celulose S/A, Rod. BR 158 - KM 231, CEP 79641300, Três Lagoas (MS), Brasil. viniciusesilva@yahoo.com.br(ORCID: 0000-0002-9422-765)

${ }^{\text {II }}$ Engenheiro Agrônomo, Mestrando em Sistemas de Produção pelo Programa de Pós-Graduação em Agronomia, Faculdade de Engenharia de Ilha Solteira, Universidade Estadual Paulista, Av. Brasil, 56, CEP 15385-000, Ilha Solteira, (SP), Brasil. pauloteodoro@agronomo.eng.br (ORCID: 0000-0002-5682-9761) / saradiaslisboa@yahoo.com.br (ORCID: 0000-0003-4125-7147) / ebatello@yahoo.com.br(ORCID: 00000001-9637-0329) / aguilarsbio@gmail.com (ORCID: 0000-0002-9895-1554) / lisboa@dracena.unesp.br (ORCID: 0000-00019013-232X) / albertinimm@hotmail.com (ORCID: 0000-0002-5131-5796)

III Engenheiro Agrônomo, Dr., Professor Adjunto do Departamento de Fitossanidade, Engenharia Rural e Solos, Faculdade de Engenharia de Ilha Solteira, Universidade Estadual Paulista, Av. Brasil, 56, CEP 15385-000, Ilha Solteira, (SP), Brasil. montanari@agr.feis.unesp.br (ORCID: 0000-0002-3557-2362)
} 


\section{Introdução}

O gênero Pinus apresenta cerca de 105 espécies identificadas, que são fisiologicamente resistentes à seca, muito exigentes em luz (suportando sombreamento apenas na fase jovem), quanto à temperatura, suportam temperaturas de $-65^{\circ} \mathrm{C}$ até $50^{\circ} \mathrm{C}$. Apresentam diferentes exigências quanto à fertilidade, textura e profundidade do solo. Devido à sua grande versatilidade possibilita o plantio em diferentes condições de ambiente (AUER; GRIGOLLETI JUNIOR; SANTOS, 2005).

A silvicultura com espécies exóticas desempenha importante papel socioeconômico no Brasil, fornecendo matéria-prima para a produção de madeira, lenha, carvão e celulose, dentre outros. Nesse sentido, torna-se necessário o aprofundamento do conhecimento sobre as variáveis ambientais que controlam a produtividade do Pinus, em especial, as edáficas.

Uma característica marcante em área reflorestada é a sua aparente homogeneidade; contudo, é frequente a observação de variações de produtividade significativas ao longo do plantio. Essas variações podem ser devidas a vários fatores, dentre eles o solo, a topografia, as variações na prática silvicultural de plantio e outros (HAKAMADA et al., 2015). É usual a adoção de um valor médio, suposto representativo, obtido de uma amostra (conjunto de parcelas), para caracterizar o estado atual e temporal da variável de interesse dentro da floresta. De acordo com Mello et al. (2005), essa variabilidade espacial pode, muitas vezes, afetar de forma marcante a qualidade das estimativas obtidas pelo inventário. Dessa forma, uma análise estatística levando em consideração a distribuição no espaço é fundamental para a avaliação do comportamento das variáveis dendrométricas.

Os atributos físicos, químicos e biológicos dos solos são importantes componentes da produtividade dos sistemas florestais, visto que as plantas necessitam de solos bem-estruturados, sendo por isso a seleção e a utilização adequada de cada tipo de solo de fundamental importância para a manutenção da qualidade e da produtividade dos sítios (MARCHÃO et al., 2007; PIGNATARO NETTO; KAT; GOEDERT, 2009; BOGNOLA et al., 2010).

De acordo com estudos feitos por Inamasu et al. (2011) é possível estabelecer Unidades de Manejo Operacional para Pinus elliotti utilizando a variável de povoamento Índice de Sítio. Isto evidencia que a técnica de geoestatística é perfeitamente aplicável utilizando variável de povoamentos de Pinus.

Diante do exposto, o objetivo do presente trabalho foi avaliar produtividade de Pinus caribaea var. hondurensis e suas relações com atributos químicos dos solos em região de cerrado brasileiro.

\section{Materiais e Métodos}

O experimento foi instalado no campus da Faculdade de Engenharia de Ilha Solteira da Universidade Estadual de São Paulo (UNESP), localizado em Selvíria, Estado de Mato Grosso do Sul (Figura 1), Brasil $\left(20^{\circ} 18^{\prime} 05^{\prime \prime} \mathrm{S}\right.$ e $20^{\circ} 18^{\prime} 28^{\prime}$ S e $52^{\circ} 39^{\prime} 02^{\prime \prime} \mathrm{W}$ e $\left.52^{\circ} 40^{\prime} 28^{\prime \prime} \mathrm{W}\right)$. A precipitação média anual é de $1.300 \mathrm{~mm}$ e a temperatura média é de $23,7^{\circ} \mathrm{C}$. O tipo climático é Aw, segundo Köppen, caracterizado como tropical úmido, com estação chuvosa no verão e seca no inverno. O solo estudado, classificado conforme Santos et al. (2006), foi o Latossolo Vermelho Distroférrico típico muito argiloso a moderado, hipodistrófico, álico, caulinítico, férrico, epicompactado, muito profundo, moderadamente ácido (DEMATTÊ, 1980).

O plantio comercial de Pinus iniciou em junho de 1986. O inventário florestal e as coletas e análises de solos foram realizadas no dia 13 de maio de 2016, tendo o Pinus nesta data 30 anos de idade. O stand inicial de plantio foi de 1.111 plantas por hectare, com arranjo 3,0 x 3,0 m. Aos 14 anos de idade, realizou-se o desbaste de 50\% dos indivíduos, utilizando-se como critério o índice multiefeitos estimado para a característica Diâmetro a Altura do Peito (DAP) (RESENDE; HIGA, 1994).

O inventário florestal foi realizado utilizando fita diamétrica para medições de Circunferência a Altura do Peito (CAP), e hipsômetro para medições de Altura total das árvores. Para todas as variáveis foram mensuradas 30 plantas e seus respectivos pontos de coleta de solo. O volume das árvores foi obtido 
através da equação proposta por Barbosa et al. (2012). As sementes das progênies que constituíram este ensaio são provenientes de um pomar de sementes clonal localizado em Aracruz-ES (latitude 1949' S, longitude $40^{\circ} 16^{\prime} \mathrm{W}$ e altitude de $50 \mathrm{~m}$ ).

\section{Figura 1 - Mapa de Localização da área experimental.}

Figure 1 - Location map of the experimental area.

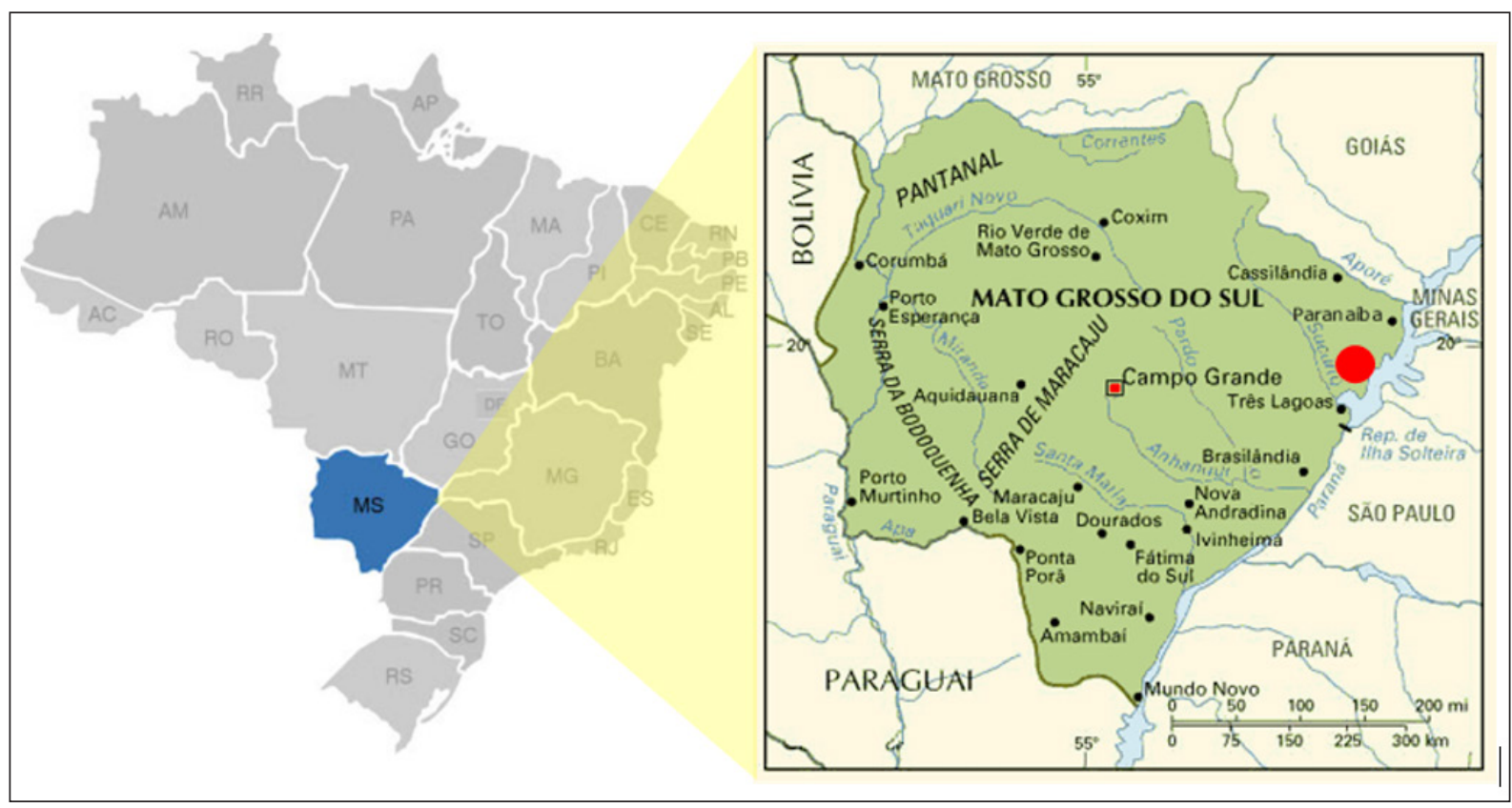

A amostragem de cada atributo do solo e da planta foi realizada no entorno dos pontos amostrais. Para os atributos químicos do solo foram determinados os teores de fósforo (P), matéria orgânica (MO), potencial hidrogeniônico $(\mathrm{pH})$, potássio $(\mathrm{K})$, cálcio $(\mathrm{Ca})$, magnésio $(\mathrm{Mg})$, acidez potencial $(\mathrm{H}+\mathrm{Al})$, alumínio (Al), soma de bases (SB), capacidade de troca catiônica (CTC), saturação por bases (V\%), cálcio $(\mathrm{CaT})$, magnésio $(\mathrm{MgT})$ e alumínio $(\mathrm{m})$ na $\mathrm{CTC}$, conforme metodologia preconizada por EMBRAPA (2006).

Foi instalada uma malha geoestatística regular $(18 \mathrm{~m} \mathrm{x} 80 \mathrm{~m})$ com pontos amostrais coletados entre 9,0 × 9,0 m (x e y), contendo 30 pontos amostrais (árvores de referência e locais de coleta de solo), intercalados de 3 em 3 entrelinhas de plantios dos Pinus, em área contínua (Figura 2).

Em todos os pontos amostrais foram realizadas avaliações dendrométricas e coletas de amostras de solos (amostragem pareada - árvore X solo), sendo as amostras de solos coletadas a distância de 1,0 metros da árvore, no sentido transversal às entrelinhas. A escolha da malha regular foi utilizando a metodologia preconizada por Barbosa et al. (2012), os autores citam que em áreas com baixa declividade e plantações homogêneas estas malhas são as mais indicadas para uma avaliação adequada de atributos de solos e plantas.

Assim, foram identificados, em função das camadas de coleta, da seguinte forma: a) para a camada de 0-0,10 m: $\mathrm{P}_{1}, \mathrm{MO}_{1}, \mathrm{pH}_{1}, \mathrm{~K}_{1}, \mathrm{Ca}_{1}, \mathrm{Mg}_{1}, \mathrm{H}+\mathrm{Al}_{1}, \mathrm{Al}_{1}, \mathrm{SB}_{1}, \mathrm{CTC}_{1}, \mathrm{~V}_{1}, \mathrm{CaT}_{1}, \mathrm{MgT}_{1}, \mathrm{~m}_{1} ; \mathrm{b}$ ) para a camada de 0,10-0,20 m: $\mathrm{P}_{2}, \mathrm{MO}_{2}, \mathrm{pH}_{2}, \mathrm{~K}_{2}, \mathrm{Ca}_{2}, \mathrm{Mg}_{2}, \mathrm{H}+\mathrm{Al}_{2}, \mathrm{Al}_{2}, \mathrm{SB}_{2}, \mathrm{CTC}_{2}, \mathrm{~V}_{2}, \mathrm{CaT}_{2}, \mathrm{MgT}_{2}$, $\mathrm{m}_{2}$.

Utilizou-se o software SAS ( 2016 para os cálculos das estatísticas descritivas: média, mediana, valores mínimo e máximo, desvio padrão, coeficiente de variação, curtose e assimetria para cada atributo estudado. Seguidamente, foram identificados os pontos anômalos (outliers), conforme identificação no gráfico de ramos e folhas, efetuando-se a substituição deles pelo valor médio dos circunvizinhos presentes na malha geoestatística para evitar que valores extremos, que geralmente não são representativos dos tratamentos médios aplicados, prejudiquem os valores médios produzidos 
pelo ecossistema produtivo de madeira (BARBOSA et al., 2012). Também foi efetuada a análise da distribuição de frequência dos dados. Desta forma, para testar a hipótese de normalidade dos atributos, foi utilizado o teste de Shapiro e Wilk (1965) a 5\%. Nele a estatística "W" testa a hipótese nula, a qual julga ser a amostra proveniente de uma população com distribuição normal. Cada atributo foi classificado de acordo com a sua proximidade em relação à distribuição normal, sendo os valores da estatística "W" menores que 0,01 classificados como distribuição indefinida (IN), entre 0,01e 0,03 tendendo a normal (TN), e acima de 0,05 distribuição normal (NO), conforme metodologia proposta por Montanari et al. (2013).

\section{Figura 2 - Coordenadas cartesianas da malha geoestatística instalada para avaliação dos atributos químicosde solo em Pinus Caribaea var. hondurensis.}

Figure 2 - Cartesian coordinates of the installed geostatistic mesh for the evaluation of soil chemical attributes in Pinus Caribaea var. hondurensis.

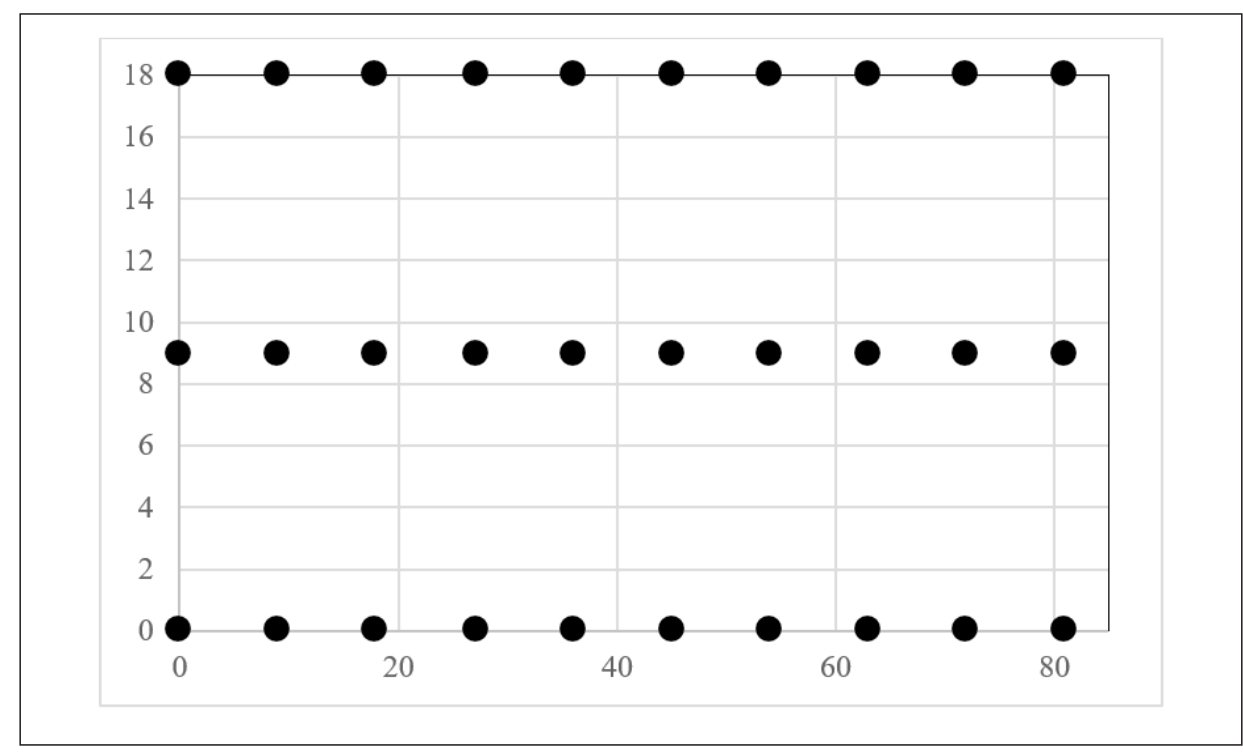

De acordo com a classificação do coeficiente de variação (CV) proposta por Pimentel-Gomes e Garcia (2002), a variabilidade de um atributo pode ser classificada segundo a magnitude de seu coeficiente de variação. Desse modo, utilizou-se também o coeficiente de variação (C.V.) em que a relação percentual entre o desvio padrão e a média, expressa de forma padronizada, o grau de dispersão da variável. De acordo com Pimentel-Gomes (1985), coeficientes de variação menores que $10 \%$, indicam variáveis de comportamento espacial, usualmente regulares; e coeficientes de variação acima de $30 \%$ são considerados muito altos.

Foi montada a matriz de correlação entre os atributos de planta e do solo pesquisados, contendo todas as combinações pareadas possíveis. Objetivou-se detectar a existência de correlações significativas entre os atributos da planta (variáveis dependentes) com os do solo (variáveis independentes). Também foi ajustada a regressão múltipla entre as variáveis dependentes (planta) versus todas as independentes (solo) objetivando selecionar aquelas que, nos devidos casos, proporcionariam as melhores relações entre causa e efeito, por intermédio do Microsoft Excel 2013 ®.

A análise espacial foi realizada pelo uso do programa geoestatístico Gamma Design Software $7.0-\mathrm{GS}^{+}{ }^{\circledR}$ (ROBERTSON, 1998). Assim, foi analisada sua dependência espacial pelo cálculo do semivariograma simples, tendo como base a pressuposição de estacionariedade da hipótese intrínseca estimada por meio da seguinte expressão (MONTANARI et al., 2013): 


$$
\hat{\gamma}(\mathrm{h})=\frac{1}{2 \mathrm{~N}(\mathrm{~h})} \sum_{\mathrm{i}=1}^{\mathrm{N}(\mathrm{h})}\left[\mathrm{Z}\left(\mathrm{X}_{\mathrm{i}}\right)-\mathrm{Z}\left(\mathrm{X}_{\mathrm{i}}+\mathrm{h}\right)\right]^{2}
$$

Em que: $\mathrm{N}(\mathrm{h})$ é o número de pares experimentais de observações $Z\left(x_{i}\right)$ e $Z\left(x_{i}+h\right)$ separados por uma distância $h$.

Assim, os semivariogramas experimentais foram ajustados pelos seguintes modelos teóricos (ISAAKS; SRIVASTAVA, 1989):

$$
\begin{aligned}
& \text { Exponencial: } \hat{\gamma}(\mathrm{h})=\mathrm{C}_{0}+\mathrm{C}\left\{1-\exp \left[-3\left(\frac{\mathrm{h}}{\mathrm{a}}\right)\right]\right\} ; \mathrm{h}>0 \\
& \text { Esférico: } \hat{\gamma}(\mathrm{h})=\mathrm{C}_{0}+\mathrm{C}\left[\frac{3}{2}\left(\frac{\mathrm{h}}{\mathrm{a}}\right)-\frac{1}{2}\left(\frac{\mathrm{h}}{\mathrm{a}}\right)^{3}\right] ; 0 \leq \mathrm{h} \leq \mathrm{A}_{0} \quad \text { então } \quad \hat{\gamma}(\mathrm{h})=\mathrm{C}_{0}+\mathrm{C} ; \mathrm{h} \geq \mathrm{a} \\
& \text { Gaussiano: } \hat{\gamma}(\mathrm{h})=\mathrm{C}_{0}+\mathrm{C}\left\{1-\exp \left[-3\left(\frac{\mathrm{h}^{2}}{\mathrm{a}}\right)\right]\right\} ; 0<\mathrm{h}<\mathrm{d}
\end{aligned}
$$

Em que: $\mathrm{C}_{0}=$ efeito pepita; $\mathrm{C}_{0}+\mathrm{C}=$ patamar; $a=$ alcance do variograma.

A análise para escolha de cada ajuste semivariográfico foi efetuada tendo como critério: a) menor soma dos quadrados dos resíduos ( $\mathrm{SQR})$; b) o maior coeficiente de determinação $\left(\mathrm{R}^{2}\right)$, e c) o maior avaliador do grau de dependência espacial (GDE), que foi determinado conforme expressão contida em Silva et al. (2017):

$$
\mathrm{GDE}=\left[\mathrm{C} /\left(\mathrm{C}+\mathrm{C}_{0}\right] .100\right.
$$

Em que: $\mathrm{GDE}=$ grau de dependência espacial; $\mathrm{C}=$ variância estrutural; $\mathrm{C}+\mathrm{C}_{0}=$ patamar.

A interpretação utilizada para o grau da dependência espacial (GDE) foi a seguinte: GDE $\leq$ $25 \%$ indicou variável espacial fracamente dependente; $25 \%<$ GDE $\leq 75 \%$ indicou variável espacial moderadamente dependente; e GDE $>75 \%$ indicou variável espacial fortemente dependente, conforme metodologia proposta por Montanari et al. (2013).

Os parâmetros dos modelos ajustados aos semivariogramas experimentais foram utilizados na estimativa dos atributos estudados em locais não amostrados por meio da técnica de krigagem ordinária. A krigagem ordinária é um dos métodos mais flexíveis e úteis para a interpolação de diferentes conjuntos de dados. Ela se diferencia das demais técnicas por buscar minimizar a variância dos erros e, em vez de tornar os pesos uma simples função da distância, incorpora a influência da dependência espacial dos dados amostrados (MOLIN; AMARAL; COLAÇO, 2015). Nesse processo, as estimativas foram feitas a partir da equação (ISAAKS; SRIVASTAVA, 1989):

$$
\mathrm{z}^{*}\left(\mathrm{x}_{0}\right)=\sum_{\mathrm{i}=1}^{\mathrm{N}} \lambda_{\mathrm{i}} \mathrm{z}\left(\mathrm{x}_{\mathrm{i}}\right)
$$

Em que: $Z^{*}=$ valor a ser estimado no ponto não amostrado $x_{0} ; \mathrm{N}=$ número de valores medidos $Z\left(x_{i}\right)$ envolvidos na estimativa; $\lambda_{i}=$ os pesos associados a cada valor medido $Z\left(x_{i}\right)$.

Para atestar a eficiência das estimativas por krigagem ordinária adotou-se, como critério final de aceitação ou não do ajuste semivariográfico, o maior coeficiente de correlação (r) entre valores observados e estimados da validação cruzada. O processo de validação cruzada, que consiste na remoção de cada observação pertencente ao conjunto de dados com subsequente estimativa do seu valor, pelo método de interpolação (krigagem ordinária), foi utilizado para a verificação da confiabilidade do modelo matemático ajustado. O modelo escolhido foi aquele que melhor estimou os valores observados, ou seja, aquele que produziu uma equação de regressão linear entre os valores observados, em função dos valores estimados o mais próximo da bissetriz (intercepto igual a zero e coeficiente angular $=1$ ) (ISAAKS; SRIVASTAVA, 1989).

Por fim, foi realizado a cokrigagem para estimação de um atributo de interesse a partir de uma covariável conforme metodologia proposta por Palmer et al. (2009) para estudos com Pinus na Nova Zelândia (NZ). 


\section{Resultados e discussão}

Na Tabela 1 observa-se que a variável Altura apresentou baixa variabilidade na área experimental, constatação que pode ser explicada pelo fato dos plantios de Pinus terem origem de progênies com grau elevado seleção ou pureza, e, consequentemente, a variação genética encontrada para os caracteres analisados foi pouco expressiva (SILVA et al., 2012); bem como pelo fato da idade do plantio ser elevada (30 anos) e, com isto, nota-se que com o aumento da idade, pode ocorrer uma homogeneização de determinados atributos dendrométricos dos plantios (Altura), tornando-os, portanto, estatisticamente mais uniformes, conforme dados observados por Hakamada et al. (2015) para cultivos de eucalipto no sudeste do Brasil.

Além disso, a variável Altura é a que melhor representa a capacidade produtiva dos sítios ou ambiente produtivos (Índice de Sítio), bem como pelo fato dela representar melhor a capacidade genética dos indivíduos (ASSIS, 2014), sendo a mesma frequentemente utilizada para a seleção genética de plantas superiores no programa de melhoramento florestal (ASSIS, 1996), e, possivelmente por apresentar a melhor estabilidade e uniformidade ao longo da rotação das plantações florestais. Tais fatos são confirmados ao se observar distribuição normal para essas variáveis (Tabela 1).

Já ao se analisar o C.V. para a variável dendrométrica DAP o mesmo foi classificado como médio; e para o atributo volume foi considerado como muito alto. Estes padrões de coeficientes de variação contrariaram os encontrados para a variável Altura (Tabela 1) e mostram que o estágio avançado de maturidade fisiológica ou mesmo a idade cronológica das plantações florestais de Pinus em questão, promoveram uma homogeneização dos parâmetros que representam a estrutura vertical das plantações florestais (Altura), e desuniformizaram as variáveis DAP e volume de Pinus. Segundo dados apresentados por Machado, Conceição e Figueiredo (2002), tratamentos mais novos de Pinus (7, 5 e 6 anos) e sem terem sofrido desbastes, apresentaram alta dispersão da base de dados de DAP e Altura, o que acarreta menor precisão dos modelos para estes tratamentos. Nos tratamentos que já haviam sofrido desbastes, observou-se aumento na precisão do ajuste, como no tratamento com 2 desbastes e 10 anos, ou seja, mais próximos à idade de rotação de Pinus, que está em torno de 14 anos. Já nos tratamentos em que o número de desbaste foi superior a 2 e a idade do plantio acima de 10 anos, observou-se queda na uniformidade quando comparados ao tratamento mais jovem e de idades intermediárias de Pinus oocarpa. Em resumo, a questão da uniformidade dos atributos dendrométricos depende fortemente da idade de avaliação das plantações florestais e do número de desbastes, sendo que as relações mais conhecidas dos índices de uniformidade (C.V., PV50, coeficiente de Gini, etc.) ocorrem mais próximas à idade de rotação, e geralmente tendem a índices de uniformidade mais altos.

A amplitude dos dados de Altura, DAP e volume foram corroborados pelos encontrados por Barbosa et al. (2012) que avaliaram experimento de Pinus aos 21 anos, porém, os valores dendrométricos encontrados neste trabalho foram 8\%, 31\% e 30\% superiores aos dados de Barbosa et al. (2012), respectivamente, provavelmente devido ao fator idade ser maior (30 anos).

Segundo os critérios estabelecidos por Raij et al. (1996) e Ribeiro, Guimarães e Venegas (1999), os teores dos nutrientes variaram de alto $\left(\mathrm{P}_{1}, \mathrm{Ca}_{1}, \mathrm{Ca}_{2}, \mathrm{Mg}_{1}, \mathrm{Mg}_{2}, \mathrm{CTC}_{1}, \mathrm{CTC}_{2}, \mathrm{CaT}_{1}, \mathrm{CaT}_{2}, \mathrm{MgT}_{1}\right.$, $\left.\mathrm{MgT}_{2}\right)$, médio $\left(\mathrm{P}_{2}, \mathrm{MO}_{1}, \mathrm{MO}_{2}\right)$, a baixo $\left[\mathrm{K}_{1}, \mathrm{~K}_{2}, \mathrm{H}+\mathrm{Al} \mathrm{l}_{1}, \mathrm{H}+\mathrm{Al}_{2}, \mathrm{SB}_{1}, \mathrm{SB}_{2}, \mathrm{~V}_{1}(\%), \mathrm{V}_{2}(\%), \mathrm{m}_{1}(\%), \mathrm{m}_{2}(\%)\right]$. Este padrão dos teores dos nutrientes pode ser explicado pela ciclagem biogeoquímica de plantações florestais, ou seja, os nutrientes com baixa mobilidade ( $\mathrm{P}, \mathrm{Ca}, \mathrm{Mg}$ ) no solo acumulam-se com o passar do tempo, enquanto os nutrientes com elevada mobilidade $(K)$, são lixiviados para camadas mais profundas e pouco acumulados no ambiente edáfico superficial, sendo este fato ainda pronunciado pela amostragem deste trabalho ter sido realizada em camadas relativamente superficiais para cultivo de espécies arbóreas (LACLAU et al., 2013).

A dispersão dos atributos químicos está de acordo com os encontrados na literatura em trabalhos com Pinus caribaea var. hondurensis e Pinus taeda (RIGATTO; DEDECEK; MATOS, 2004; RODRIGUES, 2004; BARBOSA et al., 2012). Nota-se claramente uma tendência dos nutrientes aniônicos (P) apresentarem pouca dispersão ou variação espacial, comparativamente aos catiônicos $(\mathrm{K}, \mathrm{Ca}, \mathrm{Mg})$, sendo estas diferenças atribuídas ao número de interações muito mais elevado que os aniônicos possuem no solo comparados aos catiônicos (NOVAIS et al., 2007). 
Tabela 1 - Análise descritiva dos atributos de planta e dos atributos químicos de um Latossolo Vermelho Distroférrico, na camada de 0,00-0,10 e 0,10 a 0,20 m. Selvíria-MS, 2016.

Table 1 - Descriptive analysis of the plant attributes and the chemical attributes of a dystroferric Oxisol, in the layer of 0.00-0.10 and 0.10 to $0.20 \mathrm{~m}$. Selvíria, MS state, 2016.

\begin{tabular}{|c|c|c|c|c|c|c|c|c|c|c|}
\hline \multirow{3}{*}{ Atributo } & \multicolumn{10}{|c|}{ Medidas estatísticas descritivas } \\
\hline & \multirow[t]{2}{*}{ Média } & \multirow[t]{2}{*}{ Mediana } & \multicolumn{2}{|c|}{ Valor } & \multirow[t]{2}{*}{$\begin{array}{l}\text { Desvio } \\
\text { Padrão }\end{array}$} & \multicolumn{3}{|c|}{ Coeficiente } & \multicolumn{2}{|c|}{$\begin{array}{c}\text { Probabilidade } \\
\text { do teste }\end{array}$} \\
\hline & & & Mínimo & Máximo & & $\begin{array}{c}\text { Variação } \\
(\%)\end{array}$ & Curtose & Assimetria & $\operatorname{Pr}<\mathbf{w}$ & DF \\
\hline \multicolumn{11}{|c|}{ Atributos da planta } \\
\hline Altura (m) & 26 & 26 & 23 & 33 & 3,342 & 9,5 & 0,436 & 0,69 & 0,174 & NO \\
\hline $\mathrm{DAP}(\mathrm{m})$ & 0,36 & 0,37 & 0,26 & 0,46 & 5,394 & 14,8 & $-0,523$ & $-0,139$ & 0,549 & NO \\
\hline Volume $\left(\mathrm{m}^{-3} \operatorname{arv}^{-1}\right)$ & 1,38 & 1,3 & 0,71 & 2,38 & 0,444 & 32,1 & $-0,755$ & 0,346 & 0,165 & NO \\
\hline \multicolumn{11}{|c|}{ Atributos químicos do solo } \\
\hline $\mathrm{P}_{1}\left(\mathrm{mg} \mathrm{dm}^{-3}\right)$ & 9 & 9 & 2 & 13 & 2,596 & 29,3 & 0,845 & $-0,73$ & 0,135 & NO \\
\hline $\mathrm{P}_{2}\left(\mathrm{mg} \mathrm{dm} \mathrm{m}^{-3}\right)$ & 7 & 7 & 3 & 12 & 3,565 & 37,4 & $-1,046$ & 0,215 & 0,114 & NO \\
\hline $\mathrm{MO}_{1}\left(\mathrm{~g} \mathrm{dm}^{-3}\right)$ & 21 & 21 & 11 & 32 & 4,608 & 22,2 & $-0,1$ & 0,274 & 0,577 & NO \\
\hline $\mathrm{MO}_{2}\left(\mathrm{~g} \mathrm{dm}^{-3}\right)$ & 17 & 17 & 14 & 24 & 2,608 & 15 & 0,861 & 1,041 & 0,007 & $\mathrm{IN}$ \\
\hline $\mathrm{pH}_{1}\left(\mathrm{CaCl}_{2}\right)$ & 4,4 & 4,4 & 4,1 & 5,2 & 0,274 & 6,2 & 0,217 & 0,72 & 0,028 & $\mathrm{TN}$ \\
\hline $\mathrm{pH}_{2}\left(\mathrm{CaCl}_{2}\right)$ & 4,4 & 4,3 & 4,1 & 5 & 0,285 & 6,5 & $-0,715$ & 0,752 & 0,001 & IN \\
\hline $\mathrm{K}_{1}\left(\mathrm{mmol}_{\mathrm{c}} \mathrm{dm}^{-3}\right)$ & 1 & 0,9 & 0,5 & 2,4 & 0,488 & 48,3 & 1,981 & 1,566 & 0 & IN \\
\hline $\mathrm{K}_{2}\left(\mathrm{mmol}_{\mathrm{c}} \mathrm{dm}^{-3}\right)$ & 0,8 & 0,6 & 0,3 & 1,6 & 0,456 & 60,8 & $-0,862$ & 0,796 & 0 & $\mathrm{IN}$ \\
\hline $\mathrm{Ca}_{1}\left(\mathrm{mmol}_{\mathrm{c}} \mathrm{dm}^{-3}\right)$ & 11 & 9 & 2 & 24 & 6,452 & 56,4 & $-1,158$ & 0,516 & 0,008 & $\mathrm{IN}$ \\
\hline $\mathrm{Ca}_{2}\left(\mathrm{mmol}_{\mathrm{c}} \mathrm{dm}^{-3}\right)$ & 8 & 6 & 1 & 22 & 5,758 & 69,9 & $-0,332$ & 0,892 & 0,003 & IN \\
\hline $\operatorname{Mg}_{1}\left(\mathrm{mmol}_{\mathrm{c}} \mathrm{dm}^{-3}\right)$ & 8 & 7 & 3 & 17 & 3,898 & 48,1 & $-0,658$ & 0,615 & 0,041 & $\mathrm{TN}$ \\
\hline $\operatorname{Mg}_{2}\left(\mathrm{mmol}_{\mathrm{c}} \mathrm{dm}^{-3}\right)$ & 7 & 6 & 2 & 12 & 3,381 & 52 & $-1,282$ & 0,321 & 0,014 & IN \\
\hline $\mathrm{H}+\mathrm{Al}_{1}\left(\mathrm{mmol}_{\mathrm{c}} \mathrm{dm}^{-3}\right)$ & 44 & 42 & 25 & 58 & 7,328 & 16,7 & 0,609 & $-0,492$ & 0,034 & $\mathrm{TN}$ \\
\hline $\mathrm{H}+\mathrm{Al}_{2}\left(\mathrm{mmol}_{\mathrm{c}} \mathrm{dm}^{-3}\right)$ & 39 & 38 & 28 & 52 & 6,027 & 15,5 & 0,315 & 0,132 & 0,035 & $\mathrm{TN}$ \\
\hline $\mathrm{Al}_{1}\left(\mathrm{mmol}_{\mathrm{c}} \mathrm{dm}^{-3}\right)$ & 6 & 6 & 0 & 14 & 3,841 & 63,3 & $-0,896$ & 0,133 & 0,064 & NO \\
\hline $\mathrm{Al}_{2}\left(\mathrm{mmol}_{\mathrm{c}} \mathrm{dm}^{-3}\right)$ & 6 & 6 & 0 & 12 & 3,481 & 56,8 & $-1,16$ & $-0,062$ & 0,091 & NO \\
\hline $\mathrm{SB}_{1}\left(\mathrm{mmol}_{\mathrm{c}} \mathrm{dm}^{-3}\right)$ & 20,5 & 16,8 & 7,4 & 40 & 10,229 & 50 & $-1,176$ & 0,532 & 0,006 & IN \\
\hline $\mathrm{SB}_{2}\left(\mathrm{mmol}_{\mathrm{c}} \mathrm{dm}^{-3}\right)$ & 15,9 & 12 & 3,3 & 40,2 & 9,983 & 62,9 & $-0,317$ & 0,829 & 0,011 & IN \\
\hline $\mathrm{CTC}_{1}\left(\mathrm{mmol}_{\mathrm{c}} \mathrm{dm}^{-3}\right)$ & 66,3 & 65,6 & 35,4 & 107 & 12,736 & 19,2 & 3,254 & 0,706 & 0,057 & NO \\
\hline $\mathrm{CTC}_{2}\left(\mathrm{mmol}_{\mathrm{c}} \mathrm{dm}^{-3}\right)$ & 54,1 & 54,1 & 23,7 & 74,2 & 10,146 & 18,7 & 1,863 & $-0,382$ & 0,14 & NO \\
\hline$V_{1}(\%)$ & 32 & 28 & 13 & 71 & 14,527 & 45,8 & 0,647 & 1,054 & 0,007 & $\mathrm{IN}$ \\
\hline$V_{2}(\%)$ & 29 & 25 & 7 & 69 & 15,479 & 53,7 & $-0,12$ & 0,736 & 0,061 & NO \\
\hline $\mathrm{CaT}_{1}(\%)$ & 18 & 14 & 6 & 47 & 10,087 & 56,4 & 1,512 & 1,268 & 0,002 & IN \\
\hline $\mathrm{CaT}_{2}(\%)$ & 15 & 12 & 2 & 39 & 9,908 & 64,6 & 0,159 & 0,965 & 0,009 & $\mathrm{IN}$ \\
\hline $\operatorname{MgT}_{1}(\%)$ & 12 & 11 & 5 & 26 & 4,871 & 40 & 0,588 & 0,841 & 0,059 & NO \\
\hline $\operatorname{MgT}_{2}(\%)$ & 12 & 12 & 4 & 27 & 5,756 & 47,8 & 0,295 & 0,684 & 0,134 & NO \\
\hline $\mathrm{m}_{1}(\%)$ & 27 & 28 & 0 & 63 & 18,333 & 69 & $-0,933$ & 0,166 & 0,101 & NO \\
\hline m2 (\%) & 34 & 37 & 0 & 78 & 22,734 & 67,3 & $-1,289$ & 0,024 & 0,049 & $\mathrm{TN}$ \\
\hline
\end{tabular}

Em que: $\mathrm{DAP}=$ diâmetro a Altura do peito; $\mathrm{P}($ resina $)$ = fósforo disponível; $\mathrm{MO}=$ matéria orgânica; $\mathrm{K}=$ potássio trocável; $\mathrm{Ca}=$ cálcio trocável; $\mathrm{Mg}=$ magnésio trocável; $\mathrm{Al}=$ alumínio trocável; $\mathrm{H}+\mathrm{Al}=$ acidez potencial; $\mathrm{SB}=$ soma de bases; $\mathrm{CTC}=$ capacidade de troca de cátions; $\mathrm{V}(\%)$ = saturação por bases; $\mathrm{CaT}=$ porcentagem de cálcio na $\mathrm{CTC} ; \mathrm{MgT}=$ porcentagem de magnésio na CTC; $\mathrm{m}=$ saturação por alumínio; $\mathrm{DF}=$ distribuição de frequência, sendo NO, TN e IN, respectivamente, do tipo normal, tendendo a normal e indeterminada. Números 1 e 2 precedidos correspondem à primeira $(0-0,10 \mathrm{~m})$ e segunda camada $(0,10-0,20 \mathrm{~m})$. 
Constatou-se na Tabela 2 através da compilação dos atributos de solos com os coeficientes de correlação significativos, que $71 \%$ dos atributos de solo e planta obtiveram correlação, sendo $9 \%$ correlações do tipo solo-planta, e $85 \%$ do tipo solo-solo.

Provavelmente isto se deve ao fato das variáveis de crescimento (Altura, DAP, volume) dependerem de fatores externos aos solos, como por exemplo, precipitação pluviométrica, temperatura do ar, do que dos fatores intrínsecos ao solo ou a fertilização.

Em linhas gerais, nota-se uma relação de antagonismo entre os atributos $\mathrm{H}+\mathrm{Al}_{1}, \mathrm{H}+\mathrm{Al}_{2}$, $\mathrm{Al}_{1}, \mathrm{Al}_{2}, \mathrm{~m}_{1}(\%), \mathrm{m}_{2}(\%)$ e os demais atributos químicos do solo. Provavelmente, isto se deve aos locais com microfertilidade deste experimento com elevados níveis de alumínio tóxico e de acidez potencial, possivelmente bastante ligada aos íons $\mathrm{H}^{+}$do solo, em que os demais nutrientes ficam com a sua disponibilidade comprometida devido à ocupação das cargas do solo pelo $\mathrm{H}^{+}$e $\mathrm{Al}^{+3}$ (EPSTEIN; BLOOM, 2006; NOVAIS et al., 2007).

Tabela 2 - Matriz de correlação linear entre atributos dendrométricos do Pinus caribaea var. hondurensis e atributos químicos de um Latossolo Vermelho distroférrico na camada de 0-0,10 e 0,10-0,20 m. Selvíria-MS, Brasil, 2016.

Table 2 - Linear correlation matrix between dendrometric attributes of Pinus caribaea var. Hondurensis and chemical attributes of a dystroferric Oxisol in the 0-0.10 layer and 0,10-0,20 m layer. Selvíria-MS state, Brazil, 2016.

\begin{tabular}{|c|c|c|c|c|c|c|c|c|c|c|c|c|c|c|c|c|}
\hline Atributo & DAP & Vol & $\mathbf{P}$ & MO & $\mathbf{p H}$ & $\mathbf{K}$ & $\mathrm{Ca}$ & Mg & $\mathbf{H}+\mathbf{A l}$ & Al & SB & CTC & $\mathbf{V}$ & CaT & MgT & $\begin{array}{c}\mathrm{m} \\
(\%)\end{array}$ \\
\hline Camada & \multicolumn{16}{|c|}{$0-0,10 \mathrm{~m}$} \\
\hline Altura & 0 & 0,34 & $-0,35^{*}$ & $-0,28$ & $-0,3$ & $-0,21$ & $-0,33$ & $-0,27$ & 0,01 & 0,2 & $-0,32$ & $-0,37^{*}$ & $-0,28$ & $-0,3$ & $-0,18$ & 0,24 \\
\hline DAP & 1 & $0,94 * *$ & $0,37^{*}$ & 0,21 & 0,18 & 0,13 & 0,3 & 0,21 & 0,01 & $-0,07$ & 0,28 & 0,33 & 0,22 & 0,28 & 0,14 & $-0,12$ \\
\hline Volume & $0,94 * *$ & 1 & 0,21 & 0,09 & 0,07 & 0,06 & 0,16 & 0,09 & $-0,01$ & $-0,02$ & 0,14 & 0,16 & 0,11 & 0,16 & 0,07 & $-0,05$ \\
\hline Camada & \multicolumn{16}{|c|}{$0,10-0,20 \mathrm{~m}$} \\
\hline Altura & 0 & 0,34 & $-0,38 *$ & $-0,31$ & $-0,35^{*}$ & $-0,02$ & $-0,35^{*}$ & $-0,24$ & 0,03 & 0,21 & $-0,31$ & $-0,32$ & $-0,27$ & $-0,34$ & $-0,17$ & 0,25 \\
\hline DAP & 1 & $0,94 * *$ & $0,41 *$ & 0,18 & 0,11 & 0,25 & 0,22 & 0,11 & 0,3 & $-0,04$ & 0,19 & $0,39 *$ & 0,08 & 0,13 & $-0,03$ & $-0,09$ \\
\hline Volume & $0,94 * *$ & 1 & 0,25 & 0,08 & $-0,01$ & 0,23 & 0,09 & 0,03 & 0,32 & 0,02 & 0,08 & 0,28 & $-0,02$ & 0,01 & $-0,09$ & $-0,01$ \\
\hline
\end{tabular}

Em que: Alt = Altura; DAP = diâmetro a Altura do peito; $\mathrm{Vol}=$ volume individual; $\mathrm{P}$ (resina) = fósforo disponível; $\mathrm{MO}=$ matéria orgânica; $\mathrm{K}=$ potássio trocável; $\mathrm{Ca}=$ cálcio trocável; $\mathrm{Mg}=$ magnésio trocável; $\mathrm{Al}=$ alumínio trocável; $\mathrm{H}+\mathrm{Al}=$ acidez potencial; $\mathrm{SB}=\mathrm{soma}$ de bases; $\mathrm{CTC}=$ capacidade de troca de cátions; $\mathrm{V}(\%)=$ saturação por bases; $\mathrm{CaT}=$ porcentagem de cálcio na CTC; $\mathrm{MgT}=$ porcentagem de magnésio na CTC; $\mathrm{m}$ $=$ saturação por alumínio. * $\mathrm{e}^{* *}$ significativo a $5 \%$ e a $1 \%$, respectivamente.

Nota-se ainda na Tabela 2 a forte relação do volume individual das árvores em função do DAP de Pinus caribaea var. hondurensis corroborando os dados de vários autores, sendo que o mesmo não ocorreu para a variável Altura, contrariando os dados já relatados em vasta literatura (RIGATTO; DEDECEK; MATOS, 2004; RODRIGUES, 2004; BARBOSA et al., 2012). As variáveis Altura total e diâmetro a Altura do peito (DAP) são frequentemente mencionadas como as principais características dendrométricas (SOARES; PAULA NETO; SOUZA, 2011; CAMPOS; LEITE, 2013) que determinam o volume, entretanto, a variável Altura não apresentou correlação com as variáveis volume e DAP (Tabela 2), possivelmente devido ao fator idade do povoamento de Pinus em questão ter ultrapassado o ciclo de corte normal da cultura (em torno de 14 anos por desbaste), bem como danos ocasionados por ventos nas árvores observados nas plantações de Pinus. Para o 
caso específico das correlações lineares entre volume e Altura, pode se considerar, dependendo dos autores (MUKAKA, 2012), que a correlação é classificada como fraca $(r=0,34)$; já no caso da correlação linear entre DAP e Altura é classificada como inexistente ou nula. Neste sentido, segundo dados apresentados por Inoue et al. (2011) não foram significativas as correlações entre espaço vital e Altura das árvores, nem entre espaço vital e DAP, e adicionalmente a isso, tem-se que com evolução da maturidade das plantações florestais, ocorre a estagnação do crescimento dos povoamentos após a o atingimento da idade de corte ou de desbaste, e iniciam-se a mortalidade dos indivíduos dominados ou codominados devido à forte competição intraespecífica (CAMPOS; LEITE, 2013), e as relações entre DAP e Altura, passam a não ser correlacionadas como nos plantios jovens.

Além disso, pode-se considerar outra possibilidade que o fato da Altura total ser uma das variáveis dendrométricas que pode ser utilizada para determinar o índice de sitio através do cálculo das Alturas dominantes do povoamento (SOARES; PAULA NETO; SOUZA, 2011; CAMPOS; LEITE, 2013). Entretanto, os dados encontrados neste trabalho não apresentaram concordância com outros autores (SOARES; PAULA NETO; SOUZA, 2011; BARBOSA et al., 2012; CAMPOS; LEITE, 2013), em que se observaram relações inversas, nulas ou muito fracas desta variável com os atributos de planta (Tabela 2), quanto com os de solo (Tabela 2). A hipótese exposta é o fato da variável Altura apresentar pequenos incrementos a partir do momento em que o povoamento de Pinus tornou-se adulto (instalação da forte competição intraespecífica), conforme evidenciado e comparado com outros trabalhos na Tabela 1, apresentando incrementos de $8 \%, 30$ e $31 \%$ nos atributos Altura, DAP e volume na mesma região, ou seja, os incrementos em DAP e Volume são proporcionalmente maiores que os incrementos em Altura a partir do atingimento idade técnica de corte, e isto confunde ou distorce as correlações dendrométricas positivas e fortes entre DAP X Altura e volume X Altura amplamente conhecidas na literatura.

Entre os atributos de solos avaliados, apenas $\mathrm{P}, \mathrm{pH}, \mathrm{Ca}, \mathrm{CTC}$ apresentaram correlação com os atributos de planta. Observa-se que $\mathrm{P}_{1}, \mathrm{P}_{2}$ e $\mathrm{Ca}_{2}$ apresentaram correlação negativa com o atributo de planta Altura, sugerindo que os locais de maior crescimento de Pinus foram estes em que houve maior absorção destes nutrientes pelas plantas e menores teores no solo, fato este ocasionado pela baixa mobilidade destes nutrientes nos solos, e, consequentemente, menor chance de reposição dos mesmos através das adubações de cobertura. Outro ponto são os efeitos benefícios dos fungos micorrízicos em Pinus que auxiliam na absorção seletiva e acumulo de íons no solo e de substâncias orgânicas, dificilmente disponíveis para as plantas sem micorrizas (LIMA; SOUSA, 2014). Já as variáveis $\mathrm{P}_{1}, \mathrm{P}_{2}$, e CTC $\mathrm{CT}_{2}$ apresentaram correlação positiva com a variável DAP (Tabela 2), corroborando os dados encontrados por vários autores (BARBOSA et al., 2012).

Somado a isto, pode-se atribuir à baixa relação entre os atributos de solos e de planta, a estagnação dos incrementos em crescimento do povoamento de Pinus (Altura, DAP, volume) a partir do atingimento da maturidade fisiológica do plantio, e, em contrapartida, os incrementos dos nutrientes nos solos ocorrerem de forma muito expressiva através da ciclagem de nutrientes, fortemente instalada em povoamentos adultos de Pinus (POGGIANI et al., 1987) o que prejudicou as correlações entre os atributos de solos e atributos de crescimento (Altura, DAP, volume).

Pode-se destacar ainda que a grande maioria dos atributos do solo (93\%) da camada de 0,00 0,10 m correlaciona-se com os atributos da camada 0,10-0,20 m (Tabela 3).

Nota-se que o atributo $\mathrm{H}+\mathrm{Al}$ não obteve correlação significativa entre as duas camadas e o atributo MO apresentou coeficiente de correlação classificado como baixo, e isto provavelmente é devido ao tamponamento do solo, em especial, pelos íons $\mathrm{H}+$ do solo, em que os valores das análises não foram sensíveis ou até mesmo apresentaram valores muito próximos, o que prejudicou as correlações, e isto pode ser evidenciado pela C.V destes atributos serem classificados como médio (Tabela 1).

Já o atributo CTC apresentou coeficiente de correlação classificado como médio; e os atributos $\mathrm{P}, \mathrm{pH}, \mathrm{K}, \mathrm{Ca}, \mathrm{Mg}, \mathrm{Al}, \mathrm{SB}, \mathrm{V}, \mathrm{CaT}, \mathrm{MgT}$ e $\mathrm{m}$ apresentaram coeficientes de correlação 
classificados como altos, e sugere-se com base nestas análises, que apenas os atributos acima sejam utilizados nas equações de pedotransferência devido à maior confiabilidade das suas estimativas.

Isto é muito importante do ponto de vista prático, pois permite eventuais estimativas dos atributos das camadas profundas utilizando os dados das camadas superficiais dos solos (Tabela 3 ) através de equações de pedotransferência, representando redução de custos para agricultores e laboratórios de análises de solos (FIDALSKI; TORMENA, 2007).

\section{Tabela 3 - Matriz de correlação linear de Pearson entre atributos químicos da camada 0-0,10 e 0,10-0,20 m em um Latossolo Vermelho distroférrico. Selvíria-MS, Brasil, 2016}

Table 3 - Matrix of linear correlation between chemical attributes of the $0-0.10$ layer and $0.10-0.20 \mathrm{~m}$ in a dystroferric Red Latosol. Selvíria-MS state, Brazil, 2016

\begin{tabular}{|c|c|c|c|c|c|c|c|c|c|c|c|c|c|c|}
\hline Atributos & $P_{1}$ & MO $_{1}$ & $\mathrm{pH}_{1}$ & $\mathbf{K}_{1}$ & $\mathrm{Ca}_{1}$ & $\mathbf{M g}_{1}$ & $\mathbf{H}+\mathbf{A} \mathbf{l}_{1}$ & $\mathbf{A l}_{1}$ & $\mathrm{SB}_{1}$ & $\mathrm{CTC}_{1}$ & $V_{1}$ & $\mathrm{CaT}_{1}$ & $\mathrm{MgT}_{1}$ & $\mathbf{m}_{1}$ \\
\hline $\mathrm{P}_{2}$ & $0,82 * *$ & - & - & - & - & - & - & - & - & - & - & - & - & - \\
\hline $\mathrm{MO}_{2}$ & $0,20 * *$ & $0,36^{*}$ & - & - & - & - & - & - & - & - & - & - & - & - \\
\hline $\mathrm{pH}_{2}$ & $0,42 *$ & $0,58 * *$ & $0,94 * *$ & - & - & - & - & - & - & - & - & - & - & - \\
\hline $\mathrm{K}_{2}$ & 0,17 & 0,22 & $0,71 * *$ & $0,81 * *$ & - & - & - & - & - & - & - & - & - & - \\
\hline $\mathrm{Ca}_{2}$ & $0,55 * *$ & $0,58 * *$ & $0,94 * *$ & $0,76^{* *}$ & $0,86^{* *}$ & - & - & - & - & - & - & - & - & - \\
\hline $\mathrm{Mg}_{2}$ & 0,31 & $0,50 * *$ & $0,91 * *$ & $0,62 * *$ & $0,74 * *$ & $0,89 * *$ & - & - & - & - & - & - & - & - \\
\hline $\mathrm{H}+\mathrm{Al}_{2}$ & $-0,19$ & $-0,28$ & $-0,36^{* *}$ & $-0,28$ & $-0,32$ & $-0,38^{*}$ & 0,26 & - & - & - & - & - & - & - \\
\hline $\mathrm{Al}_{2}$ & $-0,38^{*}$ & $-0,51 * *$ & $-0,80^{* *}$ & $-0,59 * *$ & $-0,69^{* *}$ & $-0,76^{* *}$ & $0,67 * *$ & $0,82 * *$ & - & - & - & - & - & - \\
\hline $\mathrm{SB}_{2}$ & $0,46^{*}$ & $0,56^{* *}$ & $0,95^{* *}$ & $0,73^{* *}$ & $0,83 * *$ & $0,88^{* *}$ & $-0,70 * *$ & $-0,78^{* *}$ & $0,88^{* *}$ & - & - & - & - & - \\
\hline $\mathrm{CTC}_{2}$ & $0,39 *$ & $0,43^{*}$ & $0,81 * *$ & $0,62 * *$ & $0,71 * *$ & $0,73 * *$ & $-0,60 * *$ & $-0,73 * *$ & $0,74 * *$ & $0,52 * *$ & - & - & - & - \\
\hline $\mathrm{V}_{2}$ & 0,46 & $0,57 * *$ & $0,89 * *$ & $0,69 * *$ & $0,79 * *$ & $0,86^{* *}$ & $-0,67 * *$ & $-0,79^{* *}$ & $0,84 * *$ & $0,60 * *$ & $0,89 * *$ & - & - & - \\
\hline $\mathrm{CaT}_{2}$ & $0,56^{* *}$ & $0,60 * *$ & $0,89 * *$ & $0,73 * *$ & $0,84 * *$ & $0,83 * *$ & $-0,63 * *$ & $-0,79 * *$ & $0,86^{* *}$ & $0,65 * *$ & $0,88 * *$ & $0,85^{* *}$ & - & - \\
\hline $\mathrm{MgT}_{2}$ & 0,27 & $0,49^{* *}$ & $0,80 * *$ & $0,50^{* *}$ & $0,65^{* *}$ & $0,83 * *$ & $-0,63^{* *}$ & $-0,71 * *$ & $0,73 * *$ & $0,49 * *$ & $0,82 * *$ & $0,73 * *$ & $0,88 * *$ & - \\
\hline $\mathrm{m}_{2}$ & $-0,41^{*}$ & $-0,53 * *$ & $-0,82 * *$ & $-0,61 * *$ & $-0,71^{* *}$ & $-0,78^{* *}$ & 0,65 & $0,87^{* *}$ & $-0,76^{* *}$ & $-0,51 * *$ & $-0,84 * *$ & $-0,78 * *$ & $-0,82 * *$ & 0,90 ** \\
\hline
\end{tabular}

Em que: $\mathrm{P}($ resina $)$ = fósforo disponível; $\mathrm{MO}=$ matéria orgânica; $\mathrm{K}=$ potássio trocável; $\mathrm{Ca}=$ cálcio trocável; $\mathrm{Mg}=$ magnésio trocável; $\mathrm{Al}=\mathrm{alumínio}$ trocável; $\mathrm{H}+\mathrm{Al}=$ acidez potencial; $\mathrm{SB}=$ soma de bases; $\mathrm{CTC}=$ capacidade de troca de cátions; $\mathrm{V}=$ saturação por bases; $\mathrm{CaT}=$ porcentagem de cálcio na $\mathrm{CTC} ; \mathrm{MgT}=$ porcentagem de magnésio na $\mathrm{CTC} ; \mathrm{m}=$ saturação por alumínio. * e ** significativo a $5 \%$ e a $1 \%$, respectivamente. Os coeficientes de Pearson destacados em vermelho representam a correlação linear entre os atributos da camada 0-0,10 e 0,10-0,20 m.

$\mathrm{Na}$ Tabela 4, observa-se que, o alcance da variável volume foi de $21,1 \mathrm{~m}$, enquanto as demais variáveis de solo apresentaram média de alcance de $36,5 \mathrm{~m}$, variando de 18,7 a $64,5 \mathrm{~m}$. Estes valores de alcance foram menores que os encontrados em trabalhos anteriores em cultivos florestais (MELLO et al., 2005; BARBOSA et al., 2012), como por exemplo, valores de alcance para volume em plantios de Eucalyptus grandis e Pinus caribaea var. hondurensis de $250 \mathrm{~m}$ e $66 \mathrm{~m}$, respectivamente.

Enquanto que foram próximos aos valores encontrados para Eucalipto em sistema silvipastoril em Ribas do Rio Pardo-MS (CORRÊA et al., 2015). O menor alcance desta pesquisa pode ter sido ocasionado pela quantidade de pontos da malha serem menores do que os outros estudos da literatura, e desse modo, dificultar ou prejudicar as comparações (PIMENTEL-GOMES; GARCIA, 2002). Todavia, o fato da grande quantidade de atributos possuírem dependência espacial é muito importante do ponto de vista do manejo florestal, uma vez que se torna possível obter os mapas de produtividade de Pinus, e, assim criar unidades de manejo de fertilização, e aplicar os tratos culturais de acordo com a capacidade produtiva de cada local e sua microfertilidade (MOLIN, 2002). 
Tabela 4 - Parâmetros dos semivariogramas simples e cruzado ajustados para características dendrométricas de Pinus caribaea var. hondurensis e de atributos químicos de um Latossolo Vermelho distroférrico, Selvíria-MS, Brasil 2016.

Table 4 - Parameters of the simple and crossed semivariograms adjusted for dendrometric characteristics of Pinus caribaeae var. hondurensis and chemical attributes of a dystroferric Oxisol, Selvíria (MS state), Brazil 2016.

\begin{tabular}{|c|c|c|c|c|c|c|c|c|c|c|c|}
\hline \multirow{3}{*}{ Atributo } & \multicolumn{11}{|c|}{ Parâmetros } \\
\hline & \multirow{2}{*}{ Modelo } & \multirow{2}{*}{$\begin{array}{r}\text { Efeito } \\
\text { Pepita } \\
\left(C_{0}\right)\end{array}$} & \multirow{2}{*}{$\begin{array}{l}\text { Patamar } \\
\left(C_{0}+C\right)\end{array}$} & \multirow{2}{*}{$\begin{array}{c}\text { Alcance } \\
\text { (m) }\end{array}$} & \multirow{2}{*}{$\mathbf{R}^{2}$} & \multirow{2}{*}{ SQR } & \multicolumn{2}{|c|}{ GDE } & \multicolumn{3}{|c|}{ Validação cruzada } \\
\hline & & & & & & & $\%$ & Classe & $\mathbf{a}$ & b & $\mathbf{r}$ \\
\hline & \multicolumn{11}{|c|}{$\gamma(\mathrm{h})$ simples dos atributos dendrométricos de Pinus } \\
\hline Altura (m) & epp & 0,38 & 7,19 & - & - & - & - & - & - & - & - \\
\hline DAP (m) & epp & 0,40 & 28,31 & - & - & - & - & - & - & - & - \\
\hline \multirow[t]{2}{*}{ Volume ( $\mathrm{m}^{3} /$ arv. $)$} & esf (48) & $5,80 \cdot 10^{-3}$ & $1,79.10^{-1}$ & 21,1 & 0,76 & $1,33.10^{-3}$ & $96 \%$ & MA & $-3,40 \cdot 10^{-1}$ & 1,25 & 0,44 \\
\hline & \multicolumn{11}{|c|}{$\gamma(\mathrm{h})$ simples dos atributos químicos do solo } \\
\hline $\mathrm{P}_{1}\left(\mathrm{mg} \mathrm{dm}^{3}\right)$ & gau (41) & $6,70.10^{-1}$ & 5,88 & 22,9 & 0,86 & 1,51 & 88,6 & MA & 1,48 & 0,83 & 0,45 \\
\hline $\left.\mathrm{P}_{2}(\mathrm{mg} \mathrm{dm})^{3}\right)$ & esf (44) & 3,92 & 8,96 & 64,5 & 0,90 & 1,95 & 56,2 & $\mathrm{ME}$ & $4,30 \cdot 10^{-1}$ & 0,94 & 0,18 \\
\hline $\left.\mathrm{MO}_{1}(\mathrm{mg} \mathrm{dm})^{3}\right)$ & esf (39) & 1,42 & $2,20.10$ & 34,6 & 0,93 & $1,16.10$ & 93,5 & MA & 2,56 & 0,88 & 0,31 \\
\hline $\mathrm{MO}_{2}\left(\mathrm{mg} \mathrm{dm}^{3}\right)$ & gau (42) & $4,00 \cdot 10^{-2}$ & 5,98 & 18,7 & 0,76 & 2,41 & 99,3 & MA & 2,84 & 0,84 & 0,41 \\
\hline $\mathrm{pH}_{1}\left(\mathrm{CaCl}_{2}\right)$ & esf (47) & $1,07.10^{-2}$ & $8,71 \cdot 10^{-2}$ & 32,6 & 0,99 & $2,82 \cdot 10^{-5}$ & 87,7 & MA & $6,00.10^{-2}$ & 0,99 & 0,39 \\
\hline $\mathrm{pH}_{2}\left(\mathrm{CaCl}_{2}\right)$ & $\exp (47)$ & $1,26.10^{-2}$ & $1,04.10^{-1}$ & 59,7 & 0,97 & $8,98 \cdot 10^{-5}$ & 87,9 & MA & $-6,00 \cdot 10^{-1}$ & 1,14 & 0,44 \\
\hline $\mathrm{K}_{1}\left(\mathrm{mmol}_{\mathrm{c}} \mathrm{dm}^{3}\right)$ & gau (42) & $2,38.10^{-2}$ & $1,96.10^{-1}$ & 24,6 & 0,99 & $1,22.10^{-4}$ & 87,8 & MA & $-7,00 \cdot 10^{-2}$ & 1,08 & 0,65 \\
\hline $\mathrm{K}_{2}\left(\mathrm{mmol}_{\mathrm{c}} \mathrm{dm}^{3}\right)$ & esf (44) & $8,97 \cdot 10^{-2}$ & $2,17.10^{-1}$ & 48 & 0,93 & $6,20.10^{-4}$ & 58,7 & $\mathrm{ME}$ & $-8,00 \cdot 10^{-2}$ & 1,11 & 0,28 \\
\hline $\mathrm{Ca}_{1}\left(\mathrm{mmol}_{\mathrm{c}} \mathrm{dm}^{3}\right)$ & gau (38) & $1,25.10$ & $4,46.10$ & 35,5 & 0,99 & 6,15 & 72 & $\mathrm{AL}$ & $5,30.10^{-1}$ & 0,95 & 0,43 \\
\hline $\mathrm{Ca}_{2}\left(\mathrm{mmol}_{\mathrm{c}} \mathrm{dm}^{3}\right)$ & gau (47) & 5,90 & $4,02.10$ & 31,2 & 0,99 & $1,07.10$ & 85,3 & MA & $-3,40.10^{-1}$ & 1,06 & 0,67 \\
\hline $\mathrm{Mg}_{1}\left(\mathrm{mmol}_{\mathrm{c}} \mathrm{dm}^{3}\right)$ & esf (43) & 4,30 & $1,83.10$ & 47,9 & 0,99 & $9,21.10^{-1}$ & 76,5 & $\mathrm{AL}$ & $9,90.10^{-1}$ & 0,88 & 0,28 \\
\hline $\mathrm{Mg}_{2}\left(\mathrm{mmol}_{\mathrm{c}} \mathrm{dm}^{3}\right)$ & esf (47) & $6,50 \cdot 10^{-1}$ & $1,34.10$ & 29,6 & 0,98 & $9,24 \cdot 10^{-1}$ & 95,1 & MA & $2,40.10^{-1}$ & 0,97 & 0,44 \\
\hline $\mathrm{H}+\mathrm{Al}_{1}\left(\mathrm{mmol}_{\mathrm{c}} \mathrm{dm}^{3}\right)$ & esf (41) & 2,90 & $5,00.10$ & 22,9 & 0,95 & $2,05.10$ & 94,2 & MA & $2,33.10$ & 0,46 & 0,07 \\
\hline $\mathrm{H}+\mathrm{Al}_{2}\left(\mathrm{mmol}_{\mathrm{c}} \mathrm{dm}^{3}\right)$ & epp & 33,17 & 33,18 & - & - & - & - & - & - & - & - \\
\hline $\mathrm{Al}_{1}\left(\mathrm{mmol}_{\mathrm{c}} \mathrm{dm}^{3}\right)$ & esf (47) & 3,47 & $1,88.10$ & 36,8 & 0,95 & 4,49 & 81,5 & MA & 1,05 & 0,82 & 0,25 \\
\hline $\mathrm{Al}_{2}\left(\mathrm{mmol}_{\mathrm{c}} \mathrm{dm}^{3}\right)$ & $\operatorname{esf}(43)$ & $5,40.10^{-1}$ & $1,11.10$ & 21,7 & 0,96 & $6,81 \cdot 10^{-1}$ & 95,1 & MA & $5,80.10^{-1}$ & 0,91 & 0,27 \\
\hline $\mathrm{SB}_{1}\left(\mathrm{mmol}_{\mathrm{c}} \mathrm{dm}^{3}\right)$ & $\operatorname{esf}(47)$ & $2,77.10$ & $1,29.10^{2}$ & 39,9 & 0,99 & $4,86.10$ & 78,4 & $\mathrm{AL}$ & 1,22 & 0,94 & 0,32 \\
\hline $\mathrm{SB}_{2}\left(\mathrm{mmol}_{\mathrm{c}} \mathrm{dm}^{3}\right)$ & gau (47) & $1,44.10$ & $1,16.10^{2}$ & 27,2 & 0,98 & $1,05.10^{2}$ & 87,6 & MA & $-9,10.10^{-1}$ & 1,07 & 0,69 \\
\hline $\mathrm{CTC}_{1}\left(\mathrm{mmol}_{\mathrm{c}} \mathrm{dm}^{3}\right)$ & $\operatorname{esf}(41)$ & $1,49.10$ & $9,58.10$ & 38,6 & 0,92 & $2,46.10^{2}$ & 84,4 & MA & $1,39.10$ & 0,79 & 0,24 \\
\hline $\mathrm{CTC}_{2}\left(\mathrm{mmol}_{\mathrm{c}} \mathrm{dm}^{3}\right)$ & esf (47) & 5,60 & $1,29.10^{2}$ & 31,9 & 0,90 & $5,12 \cdot 10^{2}$ & 95,7 & MA & $1,27.10^{1}$ & 0,77 & 0,30 \\
\hline $\mathrm{V}_{1}(\%)$ & esf (47) & $3,95.10$ & $2,56.10^{2}$ & 41,5 & 0,96 & $9,790.10^{2}$ & 84,6 & MA & $8,80 \cdot 10^{-1}$ & 0,98 & 0,38 \\
\hline $\mathrm{V}_{2}(\%)$ & gau (47) & $7,13.10$ & $2,85.10^{2}$ & 32,4 & 0,95 & $1,6710^{3}$ & 75 & $\mathrm{AL}$ & $3,40.10^{-1}$ & 0,99 & 0,45 \\
\hline $\mathrm{CaT}_{1}(\%)$ & esf (47) & $2,15.10$ & $1,224.10^{2}$ & 40,6 & 0,97 & $1,70.10^{2}$ & 82,4 & MA & $-9,00 \cdot 10^{-2}$ & 1,01 & 0,38 \\
\hline $\mathrm{CaT}_{2}(\%)$ & gau (47) & $2,58.10$ & $1,189.10^{2}$ & 33,3 & 0,97 & $1,96.10^{2}$ & 78,3 & $\mathrm{AL}$ & $-1,02$ & 1,08 & 0,57 \\
\hline $\operatorname{MgT}_{1}(\%)$ & esf (40) & 4,2 & $3,096.10$ & 50,4 & 0,92 & $3,85.10$ & 86,4 & MA & $2,70.10^{-1}$ & 0,98 & 0,35 \\
\hline $\operatorname{MgT}_{2}(\%)$ & $\operatorname{esf}(47)$ & $1,618.10$ & $3,958.10$ & 50,3 & 0,87 & $4,52.10$ & 59,1 & $\mathrm{ME}$ & 1,29 & 0,89 & 0,17 \\
\hline $\mathrm{m}_{1}(\%)$ & $\operatorname{esf}(47)$ & $3,900.10$ & $4,476.10^{2}$ & 38,3 & 0,95 & $3,42.10^{3}$ & 91,3 & MA & 2,28 & 0,91 & 0,40 \\
\hline $\mathrm{m}_{2}(\%)$ & esf (47) & $2,400.10$ & $6,061.10^{2}$ & 30,2 & 0,97 & $3,21.10^{3}$ & 96 & MA & 1,51 & 0,95 & 0,42 \\
\hline
\end{tabular}

$\gamma(\mathrm{h})$ cruzado entre atributos químicos do solo e dendrométricos de Pinus

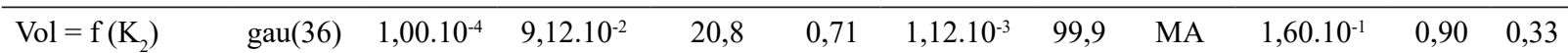

Em que: Alt =Altura; $\mathrm{DAP}=$ diâmetro a Altura do peito; $\mathrm{Vol}=$ volume individual $\mathrm{P}($ resina $)=$ fósforo disponível; $\mathrm{MO}=$ matéria orgânica; $\mathrm{K}=$ potássio trocável; $\mathrm{Ca}=$ cálcio trocável; $\mathrm{Mg}=$ magnésio trocável; $\mathrm{Al}=$ alumínio trocável; $\mathrm{H}+\mathrm{Al}=$ acidez potencial; $\mathrm{SB}=$ soma de bases; $\mathrm{CTC}=$ capacidade de troca de cátions; $\mathrm{V}(\%)=\mathrm{saturação} \mathrm{por} \mathrm{bases;}$ $\mathrm{CaT}=$ porcentagem de cálcio na $\mathrm{CTC} ; \mathrm{MgT}=$ porcentagem de magnésio na $\mathrm{CTC} ; \mathrm{m}=$ saturacão por alumínio; Números $1 \mathrm{e} 2$ precedidos correspondem à primeira $(0-0,10$ $\mathrm{m})$ e segunda camada $(0,10-0,20 \mathrm{~m})$. Gau = gaussiano, esf = esférico, com seus devidos pares de lags; $\mathrm{SQR}=$ soma dos quadrados dos resíduos; GDE = grau de dependência espacial, sendo $\mathrm{MA}=$ muito alta, $\mathrm{AL}=$ alta, $\mathrm{ME}=$ média $\mathrm{eBA}=$ baixo. 
Entretanto, pode-se inferir que do ponto vista prático, que a metodologia de manejo site específico proposta neste trabalho em termos de alcance espacial, encontra-se limitações operacionais, uma vez que os níveis tecnológicos dos pequenos produtores rurais (FREITAS, 2013) encontram-se bem aquém dos limites de precisão propostos neste trabalho, ou seja, há um elevado descolamento entre a prática e a teoria para pequenos produtores rurais, aplicando-se aos grandes produtores, principalmente empresas multinacionais (FREITAS, 2013).

$\mathrm{O}$ ajuste das mesmas apresentou excelente qualidade observando-se os valores de $\mathrm{R}^{2}$ que chegaram a $0,99\left(\mathrm{Ca}_{1}\right.$ e $\left.\mathrm{Mg}_{1}\right)$, com média de 0,94 . O avaliador de dependência espacial apresentou também excelentes ajustes com média de $80 \%$, variando de $56 \%$ a $99,3 \%$, sendo que estes parâmetros estão de acordo com os valores encontrados por vários autores (BARBOSA et al., 2012; CORREA et al., 2015; SILVA et al., 2015).A apreciável cokrigagem atestada no presente trabalho (Tabela 4; Figura 3 ) evidenciada pelo elevado valor de $\mathrm{R}^{2}(0,71)$ e sua dependência espacial (GDE $=99 \%$ ), relata a sensibilidade da produtividade do Pinus aos teores de potássio na camada de 0,10-0,20 m. Além do potássio foram encontrados cokrigagens com os atributos $\mathrm{P}_{2}, \mathrm{Mg}_{2}, \mathrm{CTC}_{2}, \mathrm{~m}_{2}$, porém, todos com coeficientes de regressão e GDE muito menores que o potássio, sendo, portanto, considerados muito baixos e pouco relevantes para estimação do volume de Pinus (PIMENTEL-GOMES; GARCIA, 2002; BARBOSA et al., 2012). Estes valores estão de acordo com os encontrados por outros autores de forma direta (ATTIWILL; ADAMS, 1996), ou seja, volume $=\mathrm{f}(\mathrm{k})$; contudo, de forma indireta através do $\mathrm{pH}$ e da CTC com outros autores (BARBOSA et al., 2012).

Figura 3 - Mapa de krigagem, semivariograma cruzado e mapa de cokrigagem para o volume de madeira de Pinus caribaea var. hondurensis em relação ao teor de potássio na camada de 0,10-0,20 m em um Latossolo Vermelho distroférrico. Selvíria-MS, Brasil, 2016.

Figure 3 - Kriging map, cross-semivariogram and cokriging map for the wood volume of Pinus caribaea var. hondurensis in relation to the potassium content in the 0,10-0,20 $\mathrm{m}$ layer in a dystroferric Oxisol. Selvíria-MS state, Brazil, 2016.

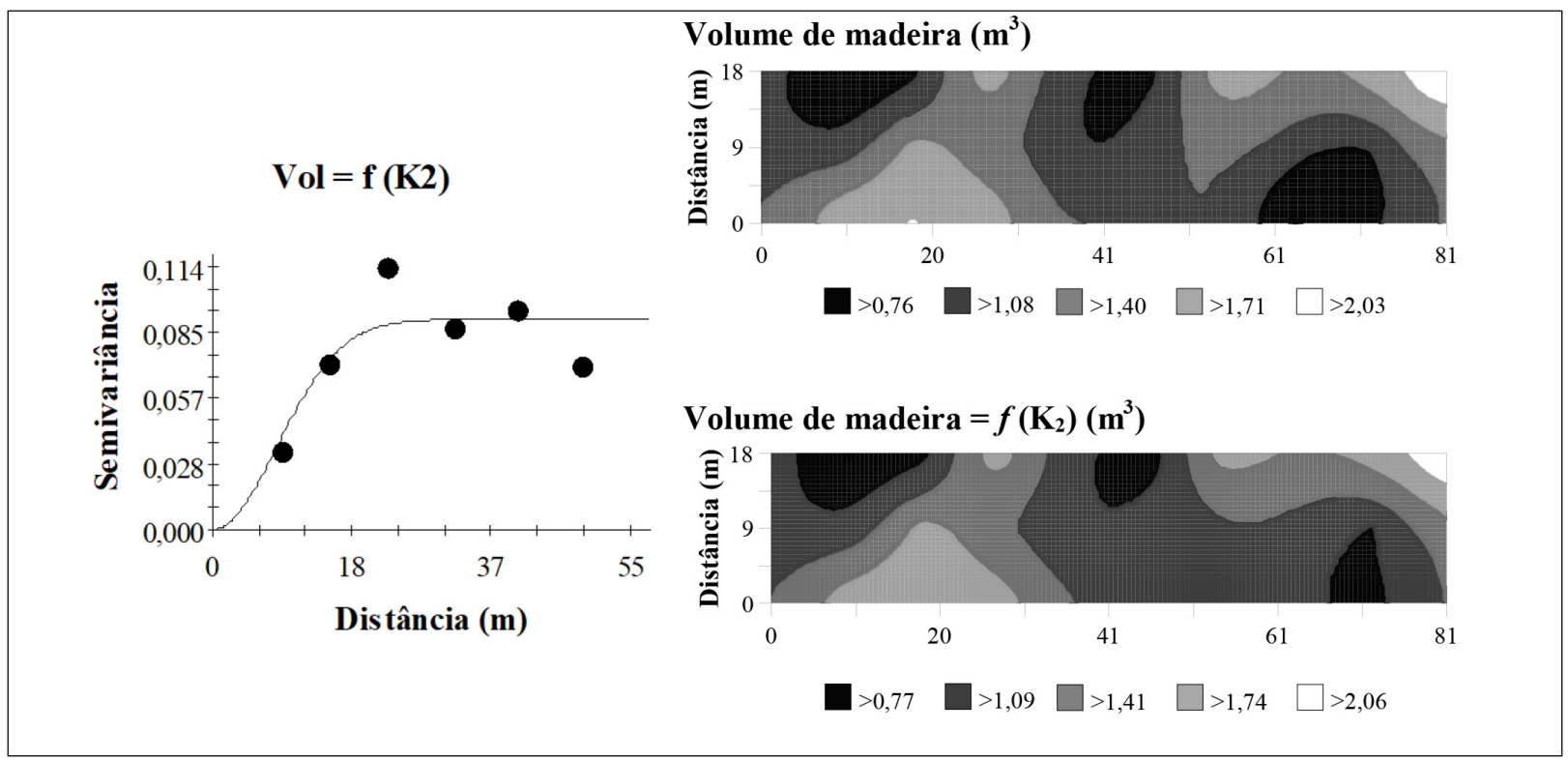

O potássio tem sido relatado como os nutrientes propulsores da produtividade em idades adultas das plantações florestais (ATTIWILL; ADAMS, 1996), possivelmente devido às suas características de regulação osmótica, bem como por ser eficiente transportador de carboidratos dos tecidos jovens para os mais velhos das árvores, ativação de aproximadamente 50 enzimas, destacando-se as sintetases, oxiredutases, desidrogenases, transferases, quinases e aldolases (MENGEL; KIRKBY, 1978; MARSCHNER, 1995; MALAVOLTA; VITTI; OLIVEIRA, 1997; EPSTEIN; BLOOM 2006). 


\section{Conclusões}

Podem-se estimar os valores dos atributos dos solos da camada de $0,10-0,20 \mathrm{~m}$ através dos atributos da camada 0,00-0,10 m (93\%), não sendo, portanto, necessária a coleta dos atributos subsuperficiais, representando oportunidades de economia em análises e coleta de solos para futuros trabalhos em áreas de Pinus no cerrado brasileiro.

Todos os atributos de solo e planta apresentaram dependência espacial simples na área do estudo, exceto Altura, DAP e H+Al da camada de 0,10-0,20 m, evidenciando que o manejo de Pinus pode ser realizado de acordo com site específico nas condições do estudo.

O potássio foi o atributo de solo que apresentou cokrigagem e dependência espacial com a produtividade de Pinus, bem como os melhores indicadores para a estimativa da produtividade.

\section{Referências}

ASSIS, T. F. Melhoramento genético do eucalipto. Informe Agropecuário, [S.1.], v. 18, n. 185, p. 32-51, 1996.

ASSIS, T. F. Melhoramenro genético de Eucalyptus: desafios e perspectivas. In: BRAZILIAN FORESTRY MEETING, 3., 2014, Campinas. Anais... [S.1.: s.n.], 2014.

ATTIWILL, P. M.; ADAMS, M. A. Nutrition of eucalyptus. Austrália: CSIRO, 1996. 448 p.

AUER, C. G.; GRIGOLleti JUNIOR, A.; SANTOS, A. F. Cultivo do Pinus. [S.1.: s.n.], 2005. (Sistemas de Produção, 5). Disponível em: <http://sistemasdeproducao.cnptia.embrapa.br/FontesHTML/Pinus/ CultivodoPinus $>$. Acesso em: 25 set. 2017.

BARBOSA, C. E. M. et al. Inter-relação da produtividade de madeira do pinus com atributos físicoquímicos de um Latossolo do cerrado brasileiro. Revista Árvore, Viçosa, MG, v. 36, n. 1, p. 25-35, nov. 2012.

BOGNOLA, I. A. et al. Influência de propriedades físico-hídricas do solo no crescimento de Pinus taeda. Pesquisa Florestal Brasileira, Colombo, v. 30, n. 61, p. 37- 49, jan. 2010.

CAMPOS, J. C. C.; LEITE, H. G. Mensuração florestal: perguntas e respostas. 4. ed. Viçosa, MG: Editora UFV, 2013. 605 p.

CORRÊA, A. R. et al. Aspects of the Silvopastoral System Correlated with Properties of a Typic Quartzipsamment (Entisol) in Mato Grosso do Sul, Brazil. Revista Brasileira de Ciência do Solo, Viçosa, MG, v. 39, n. 2, p. 438-447, mar. 2015.

DEMATTÊ, J. L. I. Levantamento detalhado dos solos do "Campus Experimental de Ilha Solteira". Piracicaba: Escola Superior de Agricultura Luiz de Queiroz, 1980. 44 p.

EMBRAPA. Centro Nacional de Pesquisa de Solos. Sistema Brasileiro de Classificação de Solos. Brasília: EMBRAPA Produção de Informação; Rio de Janeiro: EMBRAPA Solos, 2006.

EPSTEIN, E.; BLOOM, A. Nutrição mineral de plantas: princípios e perspectivas. Londrina: Planta, 2006. $403 \mathrm{p}$.

FIDALSKI, J.; TORMENA, C. A. Pedotransfer functions for the soil water retention and soil resistance to penetration under groundcover management systems in citrus. Ciência Rural, Santa Maria, v. 37, n. 5, p. 1316-1322, set. 2007.

FREITAS, G. S. Tecnologia no setor agrícola brasileiro: um olhar sob a ótica da teoria evolucionária. Revista Eletrônica de Administração e Turismo, Pelotas, v. 2, n. 1, p. 140-154, jan. 2013.

GS+. GS+ Geostatistical for environmental science. Versão 7.0, Plainwell: Gamma Design Software, 2004.

HAKAMADA, R. E. et al. Uniformidade entre Árvores durante uma rotação e sua relação com a produtividade em Eucalyptus Clonais. Cerne, Lavras, v. 21, n. 3, p. 465-472, ago. 2015.

INAMASU, R. Y. et al. Agricultura de precisão: um novo olhar. São Carlos: EMBRAPA, 2011. 334 p. 
INOUE, M. T. et al. Crescimento juvenil de Pinus taeda em função do espaço vital de crescimento. Revista Floresta, Curitiba, v. 41, n. 1, p. 57-62, jan. 2011.

ISAAKS, E. H.; SRIVASTAVA, R. M. An introduction to applied geoestatistics. New York: Oxford University, 1989. $561 \mathrm{p}$.

LACLAU, J. P. et al. Dynamics of soil exploration by fine roots down to a depth of $10 \mathrm{~m}$ throughout the entire rotation in Eucalyptus grandis plantations. Frontiers in Plant Science, Switzerland, v. 4, n. 243, p. 1-12, jul. 2013.

LIMA, F. S.; SOUSA, C. S. Growth and nutrition of eucalyptus clones seedlings inoculated with mycorrhizal fungi. Pesquisa Agropecuária Tropical, Goiânia, v. 44, n. 2, p. 110-118, abr. 2014.

MACHADO, S. A.; CONCEIÇÃO, M. B.; FIGUEIREDO, D. J. Modelagem do volume individual para diferentes idades e regimes de desbaste em plantações de Pinus oocarpa. Ciências Exatas e Naturais, Curitiba, v. 4, n. 2, p. 185-196, jul./dez. 2002.

MALAVOLTA,E.; VITTI, G.C.; OLIVEIRA, S.A.Avaliação do estado nutricional das plantas: princípios e aplicações. 2. ed. Piracicaba: Associação Brasileira para Pesquisa da Potassa e do Fosfato, 1997. 319 p.

MARCHÃO, R. L. et al. Qualidade de um latossolo vermelho sob sistemas de integração lavoura pecuária no Cerrado. Pesquisa Agropecuária Brasileira, Brasília, v. 42, n. 6, p. 873-882, jun. 2007.

MARSCHNER, H. Mineral nutrition of higher plants. San Diego: Academic Press, 1995. 888 p.

MELLO, J. M. et al. Estudo da dependência espacial de características dendrométricas para Eucalyptus grandis. Cerne, Lavras, v. 11, n. 2, p. 113-126, maio 2005.

MENGEL, K.; KIRKBY, E. A. Principles of plant nutrition. Berna: International Potash Institute, 1978. $593 \mathrm{p}$.

MOLIN, J. P. Definição de unidades de manejo a partir de mapas de produtividade. Engenharia Agrícola, Jaboticabal, v. 22, n. 1, p. 83-92, 2002.

MOLIN, J. P.; AMARAL, L. R.; COLAÇO, A. F. Agricultura de Precisão. 1. ed. São Paulo: Oficina de Textos, 2015. $101 \mathrm{p}$.

MONTANARI, R. et al. Variabilidade espacial da produtividade de sorgo e de atributos físicos em um Planossolo. Revista Agro@mbiente On-line, Roraima, v. 7, n. 3, p. 252-261, set./dez. 2013.

MUKAKA, M. M. "A guide to appropriate use of correlation coefficient in medical research. Malawi Medical Journal, [S.1.], v. 24, n. 3, p. 69-71, 2012.

NOVAIS, R. F. et al. Fertilidade do Solo. Viçosa, MG: SBCS, 2007. 1017 p.

PALMER, D. J. et al. Comparison of spatial prediction techniques for developing Pinus radiata productivity surfaces across New Zealand. Forest Ecology and Management, [S.1.], v. 258, n. 9, p. 2046-2055, oct. 2009.

PIGNATARO NETTO, I. T.; KAT, E.; GOEDERT, W. J. Atributos físicos e químicos de um Latossolo Vermelho-Amarelo sob pastagens com diferentes históricos de uso. Revista Brasileira de Ciência do Solo, Viçosa, MG, v. 33, n. 5, p. 1441-1448, jun. 2009.

PIMENTEL-GOMES, F. Curso de estatística experimental. São Paulo: Nobel, 1985. 467 p.

PIMENTEL-GOMES, F.; GARCIA, C. H. Estatística aplicada a experimentos agronômicos e florestais: exposição com exemplos e orientações para uso de aplicativos. Piracicaba: FEALQ, 2002. 309 p.

POGGIANI, F. et al. Quantificação da deposição de folhedo em talhões experimentais de Pinus taeda, Eucalyptus viminalis e Mimosa scabrella plantados em uma área degradada pela mineração do xisto betuminoso. Revista IPEF, Piracicaba, v. 37, n. 1, p. 21-29, dez. 1987.

RAIJ, B. V. et al. Recomendações de adubação e calagem para o Estado de São Paulo. 2. ed. Campinas: Instituto Agronômico, 1996. 285 p. (Boletim técnico, 100).

RESENDE, M. D. V.; HIGA, A. R. Estimação de valores genéticos no melhoramento de Eucalyptus: seleção em um caráter com base em informações do indivíduo e de seus parentes. Boletim de Pesquisa Florestal, Colombo, n. 28/29, p. 11-36, jan. 1994. 
RIBEIRO, C. A.; GUIMARÃES, P. T. G.; VENEGAS, V. H. A. Recomendações para o uso de corretivos e fertilizantes em Minas Gerais - 5 aproximação. Viçosa: CFSEMG, 1999. 359 p.

RIGATTO, P. A.; DEDECEK, R. A.; MATOS, J. L. M. Influência dos atributos do solo sobre a qualidade da madeira de Pinus taeda para produção de celulose Kraft. Revista Árvore, Viçosa, MG, v. 28, n. 2, p. 267-273, mar. 2004.

ROBERTSON, G. P. GS+: geostatistics for the environmental sciences. Michigan: Gamma Design Software, 1998. 152 p.

RODRIGUES, C. M. Efeito da aplicação de resíduo da indústria de papel e celulose nos atributos químicos, físicos e biológicos do solo, na nutrição e biomassa do Pinus taeda L. 2004. 121 f. Dissertação (Mestrado) - Universidade Federal do Paraná, Curitiba, 2004.

SANTOS, H. G. et al. Sistema brasileiro de classificação de solos. 2. ed. Rio de Janeiro: EMBRAPA Solos, 2006. 306 p.

SHAPIRO, S. S.; WILK, M. B. An analysis of variance test for normality: complete samples. Biometrika, [S.1.], v. 52, n. 3, p. 591-611, dec. 1965.

SILVA, E. N. S. et al. Variabilidade de atributos físicos e químicos do solo e produção de feijoeiro cultivado em sistema de cultivo mínimo com irrigação. Revista Brasileira de Ciência do Solo, Viçosa, MG, v. 39, n. 2, p. 598-607, jan. 2015.

SILVA, J. M. et al. Divergência genética entre progênies de Pinus caribaea var. caribaea com base em caracteres quantitativos. Pesquisa Florestal Brasileira, Colombo, v. 32, n. 69, p. 69-77, jan. 2012.

SILVA, V. E. et al. Liming influence on the spatial variability of the leaf chemical composition and in the initial growth of the Eucalyptus. Journal of Geospatial Modelling, São Luis, v. 2, n. 1, p. 1-11, jan. 2017.

SOARES, C. P. B.; PAUlA NETO, F. P.; SOUZA, A. L. Dendrometria e inventário florestal. 2. ed. Viçosa, MG: Editora UFV, 2011. 272 p. 